\title{
“TENHO PENA QUE NÃO SINALIZES QUANDO FAZES PUBLICIDADE": AUDIÊNCIA E CONTEÚDO COMERCIAL no CANal Sofia Barbosa no YouTube
}

\author{
Barbara Janiques de Carvalho \\ Faculdade de Letras, Universidade de Coimbra, Portugal / Centro Interdisciplinar de Ciências Sociais (CICS.NOVA), Portugal \\ Lidia Marôpo \\ Departamento de Ciências da Comunicação e da Linguagem, Escola Superior de Educação, Institu- \\ to Politécnico de Setúbal / Centro Interdisciplinar de Ciências Sociais (CICS.NOVA), Portugal
}

\begin{abstract}
Resumo
Este artigo trata do contexto da microcelebrização digital vivenciado por crianças e adolescentes, nomeadamente, em sites de redes sociais como o YouTube. O objetivo do trabalho está em perceber como as jovens audiências do popular canal português Sofia Barbosa, no YouTube, constroem sentidos sobre os conteúdos comerciais e a autenticidade que a youtuber apresenta. A metodologia utilizada tem cariz qualitativo e contou com a netnografia para a análise de 1.961 comentários feitos pelos subscritores em 10 vídeos publicados entre janeiro e outubro de 2018. Como forma de melhor compreender o contexto em que estavam inseridos os comentários, analisamos também os aspetos visuais, verbais e comerciais dos vídeos. Os comentários demonstram uma perceção de proximidade e intimidade por parte dos seguidores em relação à Sofia e uma forte aceitação do conteúdo comercial promovido pela jovem. No entanto, percebe-se em vários momentos uma reflexividade crítica em relação às práticas mercadológicas da youtuber, nomeadamente no que diz respeito à falta de transparência nas relações comerciais, o que se apresenta como uma oportunidade para equilibrar uma visão romantizada que muitos subscritores têm das microcelebridades com uma compreensão mais racional sobre a indústria que os sustenta.
\end{abstract}

\section{“I'M SORRY YOU DON'T FLAG IT WHEN YOU ADVERTISE": AUDIENCE AND COMMERCIAL CONTENT ON THE Sofia Barbosa YouTube CHAN Nel}

\begin{abstract}
The main theme of the article is the context of digital microcelebrity experienced by children and adolescents, particularly on social networking sites such as YouTube. The purpose of the study is to understand how young audiences of the popular Portuguese channel Sofia Barbosa on YouTube construct meaning about the commercial content and authenticity that the youtuber presents. The methodology used is qualitative bias and netnography is employed in analysing 1.961 comments made by subscribers on 10 videos posted between January and October 2018. As a means of better understanding the context of the comments we also analysed the visual, verbal
\end{abstract}


and commercial aspects of the videos. The comments demonstrate a perception on the part of followers of closeness and intimacy in relation to Sofia and a strong acceptance of the commercial content promoted by the young woman. However, critical reflections about the marketing practices of the youtuber can at various times be perceived, namely on the lack of transparency in commercial relations; this presents itself as an opportunity to balance a romanticised view that many subscribers have of microcelebrities with a more rational understanding of the industry that sustains them.

KEYwORDS

young people; microcelebrity, authenticity; commercialism; YouTube

\section{INTRODUÇÃo}

No contexto das culturas infantis e juvenis contemporâneas, as relações das crianças e adolescentes com as redes sociais têm atraído a atenção da indústria, dos media e da academia. Há muitos pontos positivos desta presença digital dos mais novos, seja como audiência ou como produtores de conteúdo: possibilidades de educação para interpretar as mensagens mediáticas, de interação e novas aprendizagens, de auto expressão e manifestação de valores e de visibilidades de suas próprias culturas (Jorge, Marôpo \& Nunes, 2018).

No entanto, o potencial de criação e amplificação de vozes, que caracterizou inicialmente a internet, cedeu espaço a um novo modelo de negócio das grandes plataformas digitais que alia a influência digital à gestão de metadados (Khamis, Ang \& Welling, 2016; van Dijck, 2017). Esta dataficação caracteriza-se pela coleta, armazenamento e monitoramento de dados sobre as sociabilidades e os comportamentos humanos, explorada por empresas, plataformas digitais e por agências governamentais. Dados que, por muito tempo, foram considerados subprodutos das novas tecnologias, como amizades, interesses pessoais, conversações, expressão de gostos e sentimentos, tornaram-se uma valiosa moeda de troca para a predição de comportamento, o desenvolvimento de novos produtos e o planeamento de ações de marketing (van Dijck, 2017).

Nesta perspetiva, plataformas como o YouTube e o Instagram passaram a investir maciçamente na profissionalização e mercantilização do conteúdo produzido pelos seus utilizadores, contribuindo para a popularidade dos chamados influenciadores digitais e para a promoção do comercialismo entre as suas audiências, compostas em grande parte por crianças e adolescentes (Jorge, Marôpo \& Nunes, 2018; Khamis et al., 2016). É neste contexto que surgem as microcelebridades, pessoas comuns que conquistam fama ao partilhar aspetos da vida quotidiana online, utilizando paralelamente estratégias de autenticidade e self-branding para atrair a atenção do público e da indústria publicitária (Banet-Weiser, 2011; Marwick, 2010).

Enquanto partilham rotinas, gostos e interesses similares aos dos seus pares, microcelebridades infantojuvenis promovem mais facilmente sentimentos de identificação perante os seus seguidores (Tomaz, 2017). Os fãs das estrelas tradicionais podem 
suscitar dúvidas se estas são como realmente se apresentam. Já as audiências das microcelebridades sentem que as conhecem verdadeiramente e que sabem detalhes que só as pessoas próximas conhecem. Desta forma, estes “'pequenos' influenciadores digitais podem ter audiências mais leais, promovendo recomendações que podem ser mais eficientes" (Jorge, Marôpo \& Nunes, 2018, p. 81).

Cerca de $70 \%$ dos espetadores adolescentes do YouTube afirmam relacionar-se mais com os influenciadores digitais do que com as celebridades tradicionais e quatro em cada 10 jovens que veem vídeos na plataforma declaram que as estrelas do YouTube as entendem melhor que os próprios amigos (O'Neil-Hart \& Blumenstein, 2016).

Neste sentido, percebe-se a importância de estudos que procurem pistas sobre os desdobramentos que esta cultura da celebrização no YouTube tem na formação das subjetividades de crianças e adolescentes e nos seus comportamentos como atores sociais e como consumidores inseridos no contexto da economia da atenção (Crawford, 2015).

Em Portugal, a cultura das microcelebridades tem conquistado espaço entre as jovens audiências. No segmento de moda e beleza, Sofia Barbosa (19 anos) é uma youtuber e instagramer com reconhecida fama. Seu canal homónimo foi selecionado como objeto empírico deste trabalho devido à sua popularidade no referido nicho no YouTube no país (Chaves, 2017), especialmente entre crianças e adolescentes. O canal tem cerca de 270 mil subscritores, 558 vídeos e quase 39 milhões de visualizações (em outubro/2019). Sofia Barbosa também mantém perfis no Instagram, no Facebook e no Twitter, todos com centenas de milhares de seguidores, e em setembro de 2019 estreou o seu próprio podcast, o Não sejas pussy. A youtuber já ganhou o prémio Nickelodeon Kids Choice Award de "Youtuber português favorita" (2017), já protagonizou campanhas publicitárias a nível nacional e, com regularidade, firma parcerias com marcas de renome internacional.

O objetivo deste artigo é perceber como as audiências do canal Sofia Barbosa constroem sentidos sobre os conteúdos comerciais e a autenticidade apresentada pela youtuber. A metodologia utilizada tem cariz qualitativo e conta com a netnografia (Fragoso, Recuero \& Amaral, 2011) para analisar os comentários dos subscritores e os conteúdos partilhados por Sofia em 10 vídeos publicados entre janeiro e outubro de 2018. Para definir o corpus da pesquisa empírica, procedeu-se à análise de conteúdo (Igartua \& Humanes, 2004) de 50 vídeos do canal, bem como ao desenvolvimento de rankings dos vídeos mais populares e com mais interação, segundo métricas como visualizações, likes, dislikes e comentários.

\section{MICROCELEBRIDADES E AS SUAS JOVENS AUDIÊNCIAS: VIVÊNCIAS EM REDE}

O século XXI chegou trazendo uma completa reinvenção da cultura do consumo e da forma de se relacionar e estar no mundo. O processo de globalização conectou pessoas e os novos aparatos criativos e tecnológicos alteraram a linearidade da comunicação, deram voz aos sujeitos, apagaram os limites entre produtor e consumidor de conteúdo, transformaram o relacionamento empresa/cliente e impuseram ao mercado uma rápida adaptação (Castells, 2007; Lipovetsky \& Seroy, 2010). 
Considerando os múltiplos recortes sociais e culturais das sociedades ocidentalizadas, sabe-se que, em geral, os jovens, hoje, estão presentes digitalmente, interagem nas redes sociais e atraem a atenção da indústria, cada vez mais vigilante ao que estão a produzir e a consumir no ambiente digital. Os estudos abaixo, realizados em diferentes contextos e países, corroboram esta afirmação.

A pesquisa Uniquely gen Z (NRF \& IBM, 2017) feita com 15.000 jovens de 13 a 21 anos, de 16 países, apontou que $74 \%$ dos participantes afirmaram gastar o seu tempo livre na internet. O estudo destacou o potencial de consumo deste segmento, de US\$44 mil milhões ao ano, e também apresentou algumas características sobre o seu comportamento de consumo e o nível de interação que estabelece com as empresas em ambiente digital: $36 \%$ afirmaram que criariam conteúdo digital para alguma marca; $42 \%$ participariam de atividades online para uma campanha; $66 \%$ demonstraram preocupação com a qualidade do que estão a comprar e $45 \%$ confirmaram o interesse por marcas eco-friendly e socialmente responsáveis.

A pesquisa Teens, social media Q technology 2018 (Anderson \& Jiang, 2018) feita com 743 adolescentes de 13 a 17 anos nos Estados Unidos indica que $45 \%$ dos participantes afirmaram estar online "quase sempre" e $44 \%$ indicaram que se conectam à internet "várias vezes ao dia". Em relação às redes sociais, o YouTube é a preferida dos adolescentes $(85 \%)$, seguido pelo Instagram $(72 \%)$ e pelo Snapchat $(69 \%)$.

No âmbito europeu, um estudo desenvolvido com 281 adolescentes de 12 a 19 anos de Portugal, Itália e Espanha (Pereira, Moura \& Fillol, 2018), concluiu que os portugueses se apresentam como os que mais utilizam as redes sociais $(4,78)$, seguidos pelos espanhóis $(4,7)$ e italianos $(4,45)$. Nos três países, o YouTube apareceu em primeiro lugar, com $97 \%$ dos participantes a afirmarem ter uma conta na plataforma. $O W$ hatsApp surgiu em segunda posição, com $88 \%$, seguido pelo Instagram, com $73 \%$.

Ao analisar todos estes dados, percebe-se o protagonismo das redes sociais nas vivências de crianças e adolescentes em rede. O que leva à reflexão de que se estão, de facto, ocupando estes espaços digitais, a indústria não deixaria de encontrar formas de também marcar presença por meio das mais diferentes estratégias mercadológicas.

Uma destas estratégias que mais tem repercutido entre o público infantojuvenil é a parceria de marcas com microcelebridades digitais, ou seja, aqueles produtores de conteúdo comuns, mas bem-sucedidos, que entendem a importância da autopromoção, constroem uma "persona online" e a comercializam como se fossem uma marca (Senft, 2008). As microcelebridades falam nas suas redes sociais com nichos específicos de público e costumam dispensar os "intermediários" do entretenimento corporativo, como os agentes típicos das grandes celebridades (Marwick, 2010). Em meio a este discurso aparentemente íntimo e apresentado como espontâneo, a microcelebridade mostra produtos, esbatendo as barreiras entre discurso publicitário e narrativa autoral. Desta maneira, representam uma solução positiva aos bloqueios dos consumidores diante dos tradicionais esforços de persuasão (Williamsom, 2016).

Esta autopromoção por meio de estratégias semelhantes às que as marcas utilizam, despertando sentidos de intimidade e afeto no público é nomeada de self-branding 
(Khamis et al., 2016; Marwick, 2010; Raun, 2018) e está intimamente relacionada à lógica da "economia da atenção" (Crawford, 2015). Esta lógica tem a sua força motriz nas métricas como os likes, os comentários e os compartilhamentos, que podem indicar alta visibilidade e capacidade de influência das microcelebridades. Portanto, para atrair a atenção da indústria, estes influenciadores sabem que precisam manter as suas audiências fidelizadas, trabalhando a seu favor (Tomaz, 2017).

O YouTube é a rede social por excelência das microcelebridades, muito porque dedicou recursos para que os vídeos amadores de seus produtores desse lugar a um conteúdo cada vez mais profissional e suscetível de ser cooptado. A plataforma surgiu em 2005 com o objetivo de facilitar a partilha de vídeos com base no conteúdo gerado pelo usuário, sem a necessidade de muitos conhecimentos técnicos (Jorge, Amaral \& Mathieu, 2018). Em 2006, a Google comprou o YouTube e em pouco tempo este alcançou as primeiras posições no ranking dos sites mais visitados do mundo (Burgess \& Green, 2009). Desde então, a plataforma voltou os seus esforços para a profissionalização dos criadores de conteúdo. As estratégias para alcançar estes objetivos foram inúmeras: 1) o imbricado sistema de algoritmos que coopta os dados dos utilizadores para serem comercializados com os anunciantes e os classifica conforme as suas escolhas e gostos; 2) as funções sociais, como comentários e likes, 3) as listas automáticas de recomendações de vídeos; 4) o programa de parceiros do YouTube (YPP); e 5) o suporte logístico dado aos criadores de conteúdo como workshops, eventos e os estúdios de gravação equipados para a produção audiovisual dos youtubers, espalhados por todo o mundo (Burgess \& Green, 2009; Jorge, Amaral \& Mathieu, 2018). Estas estratégias de cooptação do conteúdo gerado pelos utilizadores resultam em mil milhões de dólares ao ano à plataforma (Jorge, Marôpo \& Nunes, 2018).

É neste contexto que os youtubers se tornaram uma ponte entre as marcas e os seus públicos. Ao se associar a uma microcelebridade que se apresenta de forma aparentemente íntima e autêntica às suas audiências, a marca gera credibilidade e se utiliza da reputação do influenciador construída com base no self-branding. Já a criação de uma atmosfera híbrida, por parte dos influencers, que mescla narrativa pessoal e conteúdo comercial, pode ser eficaz para fazer com que o público não perceba se o que está sendo compartilhado se trata de uma recomendação espontânea ou de um conteúdo patrocinado. Ao se tratar de crianças e adolescentes, esse tipo de estratégia pode passar de maneira ainda mais desapercebida. Sampaio e Cavalcante (2016) comentam que este público identifica mais facilmente a publicidade veiculada nos meios eletrónicos que nos digitais, justamente porque o conteúdo e a publicidade, em meio online, muitas vezes, não tem demarcações bem definidas. Além disto, a cultura de pares exerce forte influência na formação das subjetividades dos mais jovens. Youtubers de sucesso parecem que estão sempre a conversar, falam a partir dos seus ambientes domésticos, sobre assuntos rotineiros, expressam-se de maneira afetuosa ou cómica, reforçam a autoestima dos seguidores, usam jargões padronizados e uma narrativa informal (Marôpo, Sampaio \& Pereira, 2018). Também falam de questões comuns ao universo pop (músicas, cinema, best-sellers, fast foods) e dos modos de ser da juventude. Ou seja, constroem relações 
para serem percebidas como autênticas e que impactam nas novas formas de socialização e de consumo de crianças e adolescentes conectadas digitalmente.

\section{ESCOLHAS METODOLÓGICAS}

Este artigo tem origem na investigação realizada no âmbito da dissertação de mestrado em Ciências da Comunicação, pela Universidade do Minho (Carvalho, 2019). Ele analisa como as audiências do canal Sofia Barbosa constroem sentidos sobre os conteúdos comerciais e a autenticidade que a youtuber apresenta. A escolha do canal deveu-se à sua popularidade entre adolescentes, especialmente no nicho de moda e beleza, no YouTube em Portugal. Aos 12 anos, Sofia via-se como uma menina tímida e afirma ter criado o seu canal como hobby, inspirada em youtubers internacionais de beleza (TEDx Talks, 2018). Hoje, aos 19 anos, a jovem comanda um canal com mais de 270 mil inscritos e quase 39 milhões de visualizações. A decisão de não ir para a universidade e mudar-se com a irmã, do Porto para a capital, Lisboa, a fim de investir na carreira, além da qualidade técnica dos vídeos, os investimentos em equipamentos e, principalmente, o facto de Sofia fazer do canal o seu trabalho a tempo inteiro, são alguns dos elementos que atestam a sua profissionalização. Os vídeos de Sofia Barbosa costumam apresentar um mix das frivolidades do dia-a-dia e do glamour que o universo da microcelebrização proporciona: Sofia limpa a sua casa, é convidada para lançamentos de produtos, fotografa looks para conhecidas marcas de roupa, pede entrega de pizza aos domingos e viaja para esquiar a convite de um patrocinador.

Este estudo teve como base a metodologia qualitativa respaldada na análise netnográfica (Fragoso et al. 2011), no sentido de promover a análise sistemática dos comentários dos subscritores e das práticas de consumo e sociabilidades protagonizadas pela jovem Sofia em 10 vídeos publicados em seu canal.

Para a seleção do corpus recorreu-se à análise de conteúdo (Igartua \& Humanes, 2004) e à classificação de todos os vídeos partilhados pela youtuber no período de janeiro a outubro de 2018 . Ao todo, 50 vídeos foram classificados em três diferentes esferas, segundo modelo de Florencia García-Rapp (2017): 1) esfera da comunidade - vídeos de self-branding, com a influenciadora a falar de si, assuntos da vida íntima, em tom pessoal, como se estivesse a conversar com uma amiga; 2) esfera comercial - a vlogger mostra as suas últimas compras ou "recebidos", experimenta produtos, ensina a usá-los e apresenta marcas; 3) esfera híbrida - identificada neste trabalho para categorizar os vídeos que mesclam estilo e conteúdo das duas esferas acima e que, muitas vezes, corresponde aos vídeos patrocinados. Esta classificação identificou 21 vídeos pertencentes à esfera da comunidade, 12 vídeos referentes à esfera comercial e 17 da esfera híbrida.

Para a análise pormenorizada dos comentários, foi selecionada uma amostra de 10 vídeos baseada em dois critérios. O primeiro se refere a um equilíbrio entre estas três esferas. O segundo critério leva em consideração as métricas de popularidade e interação dos vídeos (likes, dislikes, comentários e visualizações) que representam feedbacks concretos do que os seguidores mais apreciam (Tomaz, 2017). Estes critérios de seleção garantiram a representatividade numérica dos comentários analisados - num total de 


\section{1 - ao mesmo tempo que possibilitou uma diversidade da amostra conforme referido} na Tabela 1 abaixo.

\begin{tabular}{cll}
\hline TítUlo & \multicolumn{1}{c}{ ESFERA } & \multicolumn{1}{c}{ SINOPSE } \\
\hline "Vlog: primeiros passos & Comunidade & O vídeo mais assistido de 2018. Mescla cenas em casa, \\
para a minha mudança" & com imagens externas, que incluem viagem de comboio \\
& & de Porto para Lisboa e visitas a casas para arrendar na \\
& capital. A mudança de casa é o tema central, mas parte \\
& do vídeo dedica-se a mostrar produtos de beleza. \\
\hline
\end{tabular}

“Tag: 13 perguntas pessoais" Comunidade Este vídeo aparece em três rankings: mais visualizações,
mais comentários e mais likes. Em estilo conversacional, Sofia fala frontalmente para a câmara e responde perguntas como "duas coisas que te irritam?", "o que costuma pedir no Starbucks?" e "um guilty pleasure?".

\begin{tabular}{|c|c|c|}
\hline “Nova casa em Lisboa!” & Híbrida & $\begin{array}{l}\text { Vídeo patrocinado por uma marca de cosméticos. O título } \\
\text { sugere que Sofia irá mostrar a nova casa, entretanto o foco } \\
\text { ficou em torno dos produtos do patrocinador, os mesmos } \\
\text { apresentados no "Vlog: primeiros passos para a minha } \\
\text { mudança". É um dos vídeos que mais recebeu dislikes. }\end{array}$ \\
\hline $\begin{array}{l}\text { "A minha rotina matinal } \\
\text { para os fins de semana" }\end{array}$ & Híbrida & $\begin{array}{l}\text { Vídeo patrocinado por outra marca de cosméticos. } \\
\text { Sofia protagoniza uma rotina de cuidados estéticos. } \\
\text { As cenas mostram-na a acordar, tomar o café e a } \\
\text { se maquilhar. Nota-se um estilo de edição diferen- } \\
\text { te, em que a youtuber não se dirige à câmara e a } \\
\text { narração é em off, alternada com trilha sonora. }\end{array}$ \\
\hline “Lookbook swimwear 2018” & Comercial & $\begin{array}{l}\text { Em formato videoclipe, Sofia está na praia a "des- } \\
\text { filar" vários biquínis da marca patrocinadora. Não } \\
\text { há falas nem narração, apenas uso de banda sono- } \\
\text { ra. Na caixa de descrição há informações sobre os } \\
\text { biquínis e links para compra no site da marca. }\end{array}$ \\
\hline “Chegou ao fim!" & Comunidade & $\begin{array}{l}\text { O segundo vídeo mais visto do ano tem estilo con- } \\
\text { fessional, alto grau de subjetividade, com Sofia a } \\
\text { partilhar os anseios do fim da vida escolar. Imagens } \\
\text { do quarto de Sofia são intercaladas por imagens da } \\
\text { youtuber junto com os amigos no baile de formatura. }\end{array}$ \\
\hline $\begin{array}{l}\text { “Maquilha e fala: não vou para a } \\
\text { faculdade e a minha alimentação" }\end{array}$ & Híbrida & $\begin{array}{l}\text { Um vídeo que mescla estilo e conteúdo da esfera } \\
\text { da comunidade e da esfera comercial. Enquanto se } \\
\text { maquilha, Sofia comenta alguns assuntos abordados } \\
\text { pelos seguidores. Fala sobre a pressão social para } \\
\text { ir logo para a universidade ao mesmo tempo em } \\
\text { que menciona a marca do blush que está a usar. }\end{array}$ \\
\hline “Weekly vlog: sou uma tia babada!” & Comunidade & $\begin{array}{l}\text { A youtuber partilha a sua rotina semanal. Conver- } \\
\text { sa na sala da nova casa, prepara uma omelete, } \\
\text { passa roupa e intercala com imagens externas em } \\
\text { uma sessão de fotos, a visita a bebé de uma ami- } \\
\text { ga também youtuber e em passeio à praia. }\end{array}$ \\
\hline “O tempo passa rápido" & Híbrida & $\begin{array}{l}\text { Vídeo comemorativo dos seis anos do canal. Edição } \\
\text { que se assemelha a um videoclipe com narração em } \\
\text { offe imagens de Sofia a caminhar por Lisboa sempre } \\
\text { a segurar um caderno da marca patrocinadora, en- } \\
\text { quanto relembra momentos marcantes do seu canal. }\end{array}$ \\
\hline “Haul back to school 2018 " & Comercial & $\begin{array}{l}\text { O vídeo que mais recebeu dislikes no ano apresenta a you- } \\
\text { tuber sentada no chão do seu quarto mostrando e experi- } \\
\text { mentando várias peças de roupas que ganhou e comprou. } \\
\text { Algumas peças são da marca patrocinadora do vídeo. }\end{array}$ \\
\hline
\end{tabular}


Observamos os comentários dos 10 vídeos considerando: 1) os temas abordados; 2) a interação dos seguidores com a youtuber e com outros seguidores no que diz respeito a conteúdos comerciais; 3 ) os pedidos de informação dos seguidores sobre produtos e marcas; 4) as suas perceções sobre a autenticidade da youtuber em relação a conteúdos comerciais, e 5) aprovação ou criticismo em relação aos conteúdos comerciais. Ao todo, foram analisados 1961 comentários e respostas de comentários, recuperados por meio do YouTube Comment Scraper ${ }^{1}$ e organizados em uma planilha eletrónica. Como forma de melhor compreender o contexto em que estavam inseridos os comentários, analisamos também os vídeos, tendo em conta aspetos 1) visuais, como cenário, edição, enquadramento, pessoas que dividem a cena, atividades executadas; 2) verbais, como discurso íntimo, perguntas que faz ao público, conversa tipo tête-à-tête, atenção à autenticidade e ao que o público demonstra apreciar; e, 3) comerciais, como exibição de produtos, marcas e transparência sobre patrocínios.

\section{O QUE AS AUDIÊNCIAS PENSAM SOBRE O HIBRIDISMO QUE PROCURA CONCILIAR AUTENTICIDADE E COMERCIALISMO?}

Sofia tem uma narrativa permeada por um leve humor juvenil, que aborda assuntos de cunho pessoal e emocional. A sua retórica íntima tem função essencial na sua apresentação e é eficaz para (Carvalho, 2019, p. 98):

- identificar familiares e amigos: "neste momento estou sozinha em casa, a minha irmã foi com os meus pais para Lisboa e o meu irmão tá a trabalhar neste momento" ("Primeiros passos para a minha mudança de casa!" ");

- falar sobre a sua casa: "houve muita gente que comentou no meu último weekly vlog que a luz da minha casa é muito bonita. Como vocês podem ver, é verdade. (...) Obrigada a toda a gente que reparou nisto" ("Weekly vlog: sou uma tia babada");

- mostrar os seus hábitos: "mal eu acordo vou logo pra cozinha tomar o meu pequeno almoço e pra quem já viu os meus vlogs, já sabe o que que é. É iogurte, aveia e banana" ("A minha rotina matinal para os fins de semana");

- reforçar a ideia de que o público a conhece: "sinceramente, eu acho que vocês sabem quase tudo sobre mim" ("Tag: 13 perguntas pessoais");

- justificar uma possível falha: "hoje é domingo e antes de mais eu quero pedir desculpa porque ontem eu não gravei vlog. E sexta-feira tenho a certeza que não ficou assim um dia tão completo" ("Weekly vlog: sou uma tia babada!").

Ao consumir estes conteúdos, os seguidores se regozijam com as semelhanças de gostos demonstrados por Sofia:

CHOCOLATE BAUNILHA E CARAMELO! Amiga, eu nunca gritei tão alto SAME na minha vida! Cada vez te adoro mais. AHHH PODIAMOS SER BOAS AMIGAS. (C.F. - "Tag: 13 perguntas pessoais") ${ }^{3}$

\footnotetext{
' Ver http://ytcomments.klostermann.ca

2 Todas as falas de Sofia e comentários dos vídeos foram transcritos tal como apresentados, podendo conter erros de pontuação ou redação incorreta de alguma palavra ou frase, além de símbolos gráficos. Os emojis foram retirados.

3 Muitos utilizadores do YouTube trocam os seus nomes reais por nicknames. Todos os comentários de utilizadores
} 
Sinto-me tão orgulhosa de ti vejo te desde os meus 11 anos e agora tenho 14 e sinto que mereces tudo o que tens, quem dera um dia conhecer-te. (I.C. - "Primeiros passos para a minha mudança de casa")

Sofia és igual a mim adoro massa à bolonhesa :3. (K. G. - "Tag: 13 perguntas pessoais")

Acho que cada vez aprecio mais os teus videos Sofia. Edit: quando for da tua idade quero ter uma casa igual :). (C.F. - "Weekly vlog: sou uma tia babada")

A sensação de proximidade com a youtuber é tamanha que há seguidores que nutrem um sentimento de gratidão e uma espécie de "confiança cega" por Sofia:

Ainda não vi o video mas ja deixei like e vim dizer que és a melhor pessoa do mundo e obrigada por me dares o maior apoio psicologicamente, i love you (F. F. - "A minha rotina matinal para os fins de semana")

A narrativa íntima da youtuber torna-se exitosa quando a "Sofia amiga" se sobressai à "Sofia microcelebridade" e o trabalho no YouTube é visto como algo desinteressado ou "resultado inquestionável de uma fé inabalável na realização de um sonho ou de um empenho individual" (Tomaz, 2017, p. 162), como pode ser percebido neste comentário:

Este vídeo é tão inspirador!! Ver tudo o que conseguiste com o teu trabalho e dedicação e sem sequer esperares nada em troca. Que venham muitos mais anos de vídeos teus beijinho enorme Sofia. (S. M. - "O tempo passa rápido")

Há subscritores, que, envolvidos por sentimentos de afeto e intimidade, não percebem claramente o viés mercadológico presente no canal. Além disto, o facto das audiências aparentemente não terem muitos conhecimentos sobre como funciona a cadeia produtiva da celebridade (sistema de algoritmos, programa de parceiros, contratos publicitários, agências de marketing de influência, investimento em equipamento e tecnologia, entre outros fatores) também ajuda a construir a ideia da fama como um resultado involuntário do talento ou do esforço das jovens microcelebridades como Sofia (Tomaz, 2017).

Tão importante quanto a retórica íntima para uma estratégia de self-branding eficaz é a performance autêntica. A youtuber reforça a ideia de que é importante "ser você mesma", pela partilha de gostos (séries populares, festivais de música, lançamentos de novas marcas, dicas de viagens), pela afirmação do que define como um estilo próprio e por espontaneidade performada, ("erros" de gravação ou cenas inesperadas são mantidas na edição dos vídeos). Desta forma, enquanto grava, não pausa para abrir a porta para o entregador de pizza, ajustar o enquadramento, procurar os óculos na bolsa ou manusear o telemóvel. Em uma cena aparece sentada na sala de sua casa a falar para a

deixados nos vídeos usados neste trabalho são identificados pelas iniciais dos nomes ou nicknames, seguidas do título do vídeo no qual o comentário foi feito. 
câmara, quando desvia rapidamente a atenção para avisar à irmã que ela havia derramado leite em cima de um livro e que precisava limpar logo aquilo (Carvalho, 2019).

O público dá indícios de que percebe Sofia de forma autêntica e costuma fazer comentários maioritariamente positivos e de incentivo, usando palavras como "original", "verdadeiro", "diferente" e "sincero" (Carvalho, 2019):

... Adorei a edição e a forma como, cada vez mais, te deixas transparecer verdadeiramente para este lado :) continua. (B.C. - "Weekly vlog: sou uma tia babada!")

Muitos parabéns pelo vídeo adorei e sobretudo sei que foste muito sincera... (I.C. - "O tempo passa rápido")

Gostaria de ver mais vídeos de moda e beleza, as tuas dicas dão sempre uma ajudinha pro dia a dia. Os teus vídeos são fantásticos e originais, fico sempre surpreendida e é isso q faz com q sejas amazing!!! (F. S. - "Weekly vlog: sou uma tia babada!")

Parabéns Sofia, és um exemplo e uma inspiração tenho 12 anos e também quero criar um canal no YouTube Um grande beijinho, e continua, desejo-te tudo de bom. (C.R. - "O tempo passa rápido")

Os elogios e palavras de incentivo estendem-se às suas recomendações de produtos e marcas:

Olá sofia, (...) tenho saudades dos teus videos de favoritos ajudavam me sempre muito a descobrir novos produtos roupas ou filmes!! Beijinhos adoro te <3. (D. - "Weekly vlog: sou uma tia babada!")

O vídeo "Nova casa em Lisboa" tem o formato de vlog ${ }^{4}$ e nele a youtuber intercala cenas dentro de casa, falando diretamente para a câmara, com cenas externas na cidade de Lisboa. A jovem inicia a comentar sobre a mudança de casa e logo centraliza o assunto nos cuidados com a pele, alegando ter recebido muitos pedidos para que partilhasse a sua rotina de cuidados com a pele. Este é o mote para introduzir a publicidade paga de uma conhecida marca francesa de cosméticos. O vídeo de 11 minutos que, conforme sugere o título, deveria ter o foco na nova casa em Lisboa, tem cerca de quatro minutos dedicados à youtuber a apresentar os produtos da marca patrocinadora. Esta tentativa de "camuflar" o viés mercadológico por meio do título foi percebida por uma seguidora (Carvalho, 2019):

Sofia estava à espera dum vídeo a mostrares a tua nova casa. Não sei porque é que escolheste este título um pouco enganador. (C.S - "Nova casa em Lisboa")

\footnotetext{
4 Vídeos que mostram as vivências pessoais da rotina de uma microcelebridade, como um diário pessoal compartilhado diante da câmera (Marôpo et al., 2018). Sofia costuma fazer com mais frequência o que ela nomeia de weekly vlogs, em que mostra os acontecimentos de uma semana inteira.
} 
$\mathrm{Na}$ caixa de descrição havia um agradecimento à marca patrocinadora, entretanto, percebe-se, novamente, uma tentativa de manter a publicidade despercebida, ao analisar este comentário:

Adoro os teus vídeos, só tenho pena que não sinalizes quando fazes publicidade a alguma coisa, quer seja no vídeo ou na caixa de descrição é extremamente importante a sinalização das publicidades, mesmo que fosse na caixa de descrição com um *este video é patrocinado, porque claramente é patrocinado pela garnier. (C. - "Nova casa em Lisboa")

Ou seja, é provável que o agradecimento feito por Sofia tenha sido inserido em um segundo momento após o upload do vídeo. Além deste comentário a cobrar transparência, identificámos outras manifestações críticas ao conteúdo publicitário presente no canal. Um comentário, com 18 likes de outros seguidores, destaca que nos últimos meses os vídeos de Sofia "não são mais os mesmos" e que muita gente sente que a youtuber parece gravar por obrigação, por estar a receber das marcas. O autor do comentário exemplifica ao citar aquele mesmo vídeo, em que Sofia passou metade do tempo a falar de um produto e praticamente não apresentou outros conteúdos.

Percebe-se, assim, que, seja pelo título "camuflado", pela falta de menção ao patrocínio ou pela inserção casual dos produtos em meio às cenas do dia-a-dia, há um claro esforço para valorizar uma performance aparentemente autêntica do quotidiano de Sofia, em detrimento de uma maior transparência sobre o conteúdo patrocinado.

Estas estratégias de hibridização entre conteúdos da esfera comercial e da comunidade são novamente questionadas pelos subscritores no vídeo "A minha rotina matinal para os fins de semana", que tem o patrocínio de outra renomada marca de cosméticos. Este foi um dos vídeos que mais recebeu dislikes e comentários negativos. A produção assemelha-se a um videoclipe com um roteiro pré-estabelecido que conta uma história: o que Sofia faz em uma manhã de fim de semana. O vídeo se inicia com Sofia a acordar na sua cama e termina com a youtuber a passear pelo parque. Neste entremeio, Sofia utiliza inúmeros produtos para a pele e maquilhagem, todos da marca patrocinadora. Novamente a omissão do conteúdo patrocinado foi percebida, o que leva, mais uma vez, à conclusão de que a menção à publicidade presente na caixa de descrição foi incluída após a publicação e, provavelmente, depois das manifestações de desaprovação.

Também surgiram críticas sobre a ética de Sofia por utilizar produtos de empresas que testam em animais. Uma seguidora comentou:

Sofia, volto a dizer, se quiseres utilizar maquilhagem mais ética, ou seja, cruelty free não é boa ideia usares e apoiares a Clinique. Testa em animais.

(S. - "A minha rotina matinal para os fins de semana")

Contudo, foi sobre o facto de o conteúdo comercial comprometer a aparência de autenticidade promovida por Sofia que incidiram as críticas com maior repercussão entre a audiência. Este comentário recebeu 93 likes: 
Rotina só com uma marca não é uma rotina real. Não tem mal nenhum, mas fica demasiado óbvio que não é um video realista e sincero. (C. - "A minha rotina matinal para os fins de semana")

Este outro comentário também seguiu a mesma linha:

O vídeo está muito bom, mas na minha opinião não corresponde a realidade. Para começar o vídeo é patrocinado por marcas de maquilhagem e ninguém usa 10 cenas diferentes de maquilhagem antes de sair TODOS os dias... (U. - "A minha rotina matinal para os fins de semana")

Houve também quem pedisse que Sofia não deixasse a sua autenticidade ser influenciada pelos patrocínios:

...por favor não deixes de ser "tu" e não deixes de dar a tua opinião sincera sobre os produtos e as marcas, apenas por causa dos patrocínios, porque pelo menos eu sempre te segui por seres super honesta e humilde, e seria uma pena se agora o começasses a deixar de ser para com os teus subs... Beijinho. (M. M. - "A minha rotina matinal para os fins de semana")

\section{DisCUSSÃo E CONCLUSÃo}

A análise dos comentários dos seguidores do canal Sofia Barbosa neste estudo contribui para um maior entendimento das sociabilidades infantis e juvenis no âmbito da cultura do consumo promovida no ambiente digital.

As audiências retribuem as estratégias de intimidade e autenticidade de Sofia com frequentes manifestações de afeto. Os elogios, os feedbacks positivos, as tentativas em encontrar afinidades com a youtuber ou os desejos de que Sofia se tornasse, realmente, uma amiga, para além dos ecrãs, são exemplos disto. Percebe-se também nesta relação de aparente proximidade, uma forte aceitação do conteúdo comercial fomentado pela jovem.

No entanto, é possível encontrar pontualmente exemplos que indicam que os apelos ao consumo presentes no canal não são assimilados sem nenhum tipo de sentido crítico. Em diversos momentos, há uma reflexividade em relação às práticas comerciais protagonizadas por Sofia, nomeadamente quando são dissimuladas.

A falta de transparência quanto aos patrocínios, quando percebida, não encontrou uma boa receção numa pequena parcela dos subscritores. Outras estratégias para ocultar a presença do conteúdo comercial, como no caso do título visto como "enganador", também foram recebidas de forma crítica por parte do público. Alguns seguidores apontaram caminhos para resolver a questão com pedidos para que Sofia identifique sempre os conteúdos patrocinados. Embora raras, também foram encontradas manifestações críticas em relação às próprias marcas, como no caso da seguidora que questionou Sofia pelo uso de marcas que testam em animais, posicionando-se politicamente em defesa da causa. 
Esta postura mais cética de alguns seguidores pode ser interpretada como uma noção incómoda de que, repentinamente, estão sendo catapultados do posto de "amigos que tudo sabem sobre Sofia" para o lugar de meros consumidores. É possível perceber nos comentários um sentimento de deslealdade perante a artificialidade de determinados conteúdos e a tentativa da youtuber em monetizar a partir de relações comerciais com determinadas marcas e produtos que são apresentadas como genuínas.

Estas manifestações de desencantamento com a youtuber podem contribuir para equilibrar uma visão romantizada que muitos subscritores têm das microcelebridades com uma compreensão mais racional sobre a indústria que os sustenta. Neste sentido, os conteúdos comerciais em alguns momentos não foram apenas um veículo de promoção de marcas e produtos, mas transformaram-se num espaço para que os seguidores também pudessem posicionar-se criticamente no espaço dos comentários.

Nestes momentos, a jovem audiência demonstra possuir alguma literacia que a ajuda a desenvolver competências para analisar e discernir os conteúdos encontrados no canal, incluindo os mercadológicos (Pereira, Pinto \& Moura, 2015). No entanto, de uma maneira geral, os comentários demonstram que crianças e jovens pouco sabem (ou pouco se importam) sobre os processos comerciais imbricados no universo das microcelebridades digitais.

A presença de crianças e adolescentes na internet e nas redes sociais pode e deve ser interpretada também por um olhar positivo que descortina novas possibilidades para se constituírem como atores sociais que impactam o contexto à sua volta por meio da interação, da aprendizagem e da expressão das suas culturas e identidades. No entanto, há ainda um longo trabalho de literacia digital a ser feito para que crianças e jovens utilizadores das redes sociais percebam de maneira mais consciente como a indústria se tem valido da visibilidade e da credibilidade de microcelebridades como Sofia. Isto inclui não apenas as marcas, mas também os grandes conglomerados da internet, como a Google e o YouTube, que têm o seu modelo de negócio baseado na cooptação de conteúdos e audiências. É preciso mais e novos estudos neste sentido, tendo os media digitais como um amplo campo de estudo e as crianças e adolescentes como agentes fundamentais destas investigações.

\section{REFERÊNCIAS}

Anderson, M. \& Jiang, J. (2018). Teens, social media Q technology 2018. Washington: Pew Research Center. Retirado de https://www.pewresearch.org/internet/2018/05/31/teens-social-media-technology-2018/

Banet-Weiser, S. (2011). Branding the post-feminist self: girls' video production and YouTube. In M. C. Kearney (Ed.), Mediated girlhoods: new explorations of girls' media culture (pp. 277-294). Nova lorque: Peter Lang.

Burgess, J. \& Green, J. (2009). YouTube e a revolução digital: como o maior fenômeno da cultura participativa transformou a mídia e a sociedade. São Paulo: Aleph.

Castells, M. (2007). A galáxia internet. Reflexões sobre internet negócios e sociedade. Lisboa: Fundação Calouste Gulbenkian. 
Carvalho, B. J. (2019). Entre o afeto e o consumo: perceções e interações de uma jovem youtuber e suas audiências. Dissertação de Mestrado, Universidade do Minho, Braga, Portugal. Retirado de http:// repositorium.sdum.uminho.pt/handle/1822/61234

Chaves, S. (2017, 19 de novembro). 8 vloggers de beleza que deve seguir no Instagram. Nit. Retirado de https://nit.pt/vanity/beleza/vloggers-beleza-seguir-instagram

Crawford, M. (2015). Introduction: attention as a cultural problem. In C. Matthew (Ed.), The world beyond your head: on becoming an individual in an age of distraction (pp. 3-28). Nova lorque: Farrar, Straus and Giroux.

Fragoso, S., Recuero, R. \& Amaral, A. (2011). Métodos de pesquisa para internet. Porto Alegre: Sulina.

García-Rapp, F. (2017). Popularity markers on YouTube's attention economy: the case of Bubzbeauty. Celebrity Studies, 8(2), 228-245. https://doi.org/10.1080/19392397.2016.1242430.

Igartua, J. \& Humanes, M. (2004). El método científico aplicado a la investigación en comunicación social. Aula abierta, Lecciones básicas. Portal de la Comunicación. Retirado de https://www.researchgate.net/ profile/Maria_Humanes/publication/237584442_El_metodo_cientifico_aplicado_a_la_investigacion_ en_comunicacion_social/links/oob49526104d2d148500000o/El-metodo-cientifico-aplicado-a-lainvestigacion-en-comunicacion-social.pdf

Jorge, A., Amaral, I. \& Mathieu, D. (2018). The co-option of audiences in the attention economy: introduction. Observatório [Vol. Especial], 1-4.

Jorge, A., Marôpo, L. \& Nunes, T. (2018). 'I am not being sponsored to say this': a teen youtuber and her audience negotiate branded content. Observatório [Vol. Especial], 76-96.

Khamis, S., Ang, L. \& Welling, R. (2016). Self- branding, 'micro-celebrity' and the rise of Social Media Influencers. Celebrity Studies, 18, 1-18. http://dx.doi.org/10.1080/19392397.2016.1218292

Lipovetsky, G. \& Serroy, J. (2010). O ecrã global: cultura mediática e cinema na era hipermoderna. Lisboa: Edições 70.

Marôpo, L., Sampaio, I. \& Pereira, N. (2018). Meninas no YouTube: participação, celebrização e cultura do consumo. Estudos em Comunicação, 16(1), 175-195.

Marwick, A. E. (2010). Status update: celebrity, publicity and self-branding in web 2.o. Tese de Doutoramento, New York University, Nova lorque, EUA. Retirado de https://www.academia.edu/27795511/ Status_Update_Celebrity_Publicity_and_Self_Branding_in_Web_2.o_PhD_Dissertation

NRF \& IBM. (2017). Uniquely gen Z: executive report. Retirado de https://nrf.com/research/uniquely-gen-z

O'Neil-Hart, C. \& Blumenstein, H. (2016, junho). Why YouTube stars are more influential than traditional celebrities [Post em blogue]. Retirado de https://goo.gl/7YdeSD

Pereira, S., Moura, P. \& Fillol, J. (2018). The youtubers phenomenon: what makes YouTube stars so popular for young people? Fonseca, Journal of Communication, 17, 107-123.

Pereira, S., Pinto, M. \& Moura, P. (2015). Níveis de literacia mediática: estudo exploratório com jovens do $12^{\circ}$ ano. Braga: CECS.

Raun, T. (2018). Capitalizing intimacy: New subcultural forms of micro- celebrity strategies and affective labour on YouTube. Convergence: The International Journal of Research into New Media Technologies, 24(1), 99-113. https://doi.org/10.1177/1354856517736983.

Sampaio, I \& Cavalcante, A. (2016). Publicidade infantil em tempos de convergência. Relatório final, Universidade Federal do Ceará, Ceará, Brasil. 
Senft, T. (2008). Camgirls: celebrity and community in the age of social networks. Estados Unidos: Peterlang.

TEDx Talks. (2018). "Nunca Digas Nunca" / Sofia Barbosa / TEDxBraga. Retirado de https://www.youtube.com/ watch?v=gtxNZwcwDgs

Tomaz, R. (2017). O que você vai ser antes de crescer: youtubers, infância e celebridade. Tese de Doutoramento, Universidade Federal do Rio de Janeiro, Rio de Janeiro, Brasil.

Van Dijck, J. (2017). Confiamos nos dados? As implicações da datificação para o monitoramento social. Matrizes, 11(1), 39-59. https://doi.org/10.11606/issn.1982-8160.v11i1p39-59

Williamson, D. (2016, 4 de março). Como as marcas podem usar influenciadores. Meio e Mensagem. Retirado de http://www.meioemensagem.com.br/home/marketing/2016/03/04/como-as-marcas-podem-usarinfluenciadores.html

\section{NOTAS BIOGRÁFICAS}

Bárbara Janiques de Carvalho é doutoranda em Ciências da Comunicação na Universidade de Coimbra (Portugal) e investigadora no Centro Interdisciplinar de Ciências Sociais da Universidade NOVA de Lisboa (Portugal). A sua investigação combina os media interativos, literacia mediática, cultura das microcelebridades e formas de socialização de crianças e adolescentes em redes sociais digitais. Possui mais de 10 anos de experiência trabalhando no setor de comunicação de organizações não-governamentais no Brasil, com assessoria de imprensa, produção de eventos, social media, marketing digital e copywriting.

ORCID: https://orcid.org/oooo-0001-6203-7333

Email: bjaniques@gmail.com

Morada: Faculdade de Letras da Universidade de Coimbra - Largo Porta Férrea, 3000-370 Coimbra, Portugal

Lidia Marôpo é Professora Assistente no Instituto Politécnico de Setúbal, Portugal, e investigadora integrada no Centro Interdisciplinar de Ciências Sociais da Universidade NOVA de Lisboa, Portugal. É doutorada em Ciências da Comunicação pela Universidade NOVA de Lisboa (2010), onde também realizou pós-doutoramento (2011-2012). Sua investigação aborda principalmente a relação entre crianças, jovens e media, com foco especial, nos últimos anos, na cultura digital. Tem participado de projetos e redes internacionais, como as "COST Actions Transforming Audiences" e "ySKILLS", e publicado em periódicos nacionais e internacionais como o Journal of Children and Media e Communication Q Society e editoras como Palgrave e Routledge.

ORCID: https://orcid.org/oooo-0003-4687-7628

Email: lidiamaropo@gmail.com

Morada: Campus do IPS, Estefanilha 2914 - 504 Setúbal | Portugal

* Submissão: 19/12/2019

* Aceitação: 09/04/2020 